\title{
FLUID-SOLID INTERCTION (FSI) ANALYSIS OF PARTIAL JOURNAL BEARING
}

DOI:

http://journals.uokufa.edu.iq/index.php/kje/article/view/9383

\section{Document Version}

Final published version

Link to publication record in Manchester Research Explorer

\section{Citation for published version (APA):}

Shamal, S. J., Al-Anasri, L., Alhusseny, A., \& Nasser, A. (2020). FLUID-SOLID INTERCTION (FSI) ANALYSIS OF PARTIAL JOURNAL BEARING. Kufa Journal of Engineering, 11(4), 72-95.

https://doi.org/http://journals.uokufa.edu.iq/index.php/kje/article/view/9383

\section{Published in:}

Kufa Journal of Engineering

\section{Citing this paper}

Please note that where the full-text provided on Manchester Research Explorer is the Author Accepted Manuscript or Proof version this may differ from the final Published version. If citing, it is advised that you check and use the publisher's definitive version.

\section{General rights}

Copyright and moral rights for the publications made accessible in the Research Explorer are retained by the authors and/or other copyright owners and it is a condition of accessing publications that users recognise and abide by the legal requirements associated with these rights.

\section{Takedown policy}

If you believe that this document breaches copyright please refer to the University of Manchester's Takedown Procedures [http://man.ac.uk/04Y6Bo] or contact uml.scholarlycommunications@manchester.ac.uk providing relevant details, so we can investigate your claim.

\section{OPEN ACCESS}




\title{
FLUID-SOLID INTERCTION (FSI) ANALYSIS OF PARTIAL JOURNAL BEARING
}

\author{
Souad Jabbar Shamal ${ }^{1}$, Luay Al-Anasri², Ahmed Alhusseny ${ }^{3}$ and Adel Nasser ${ }^{4}$ \\ ${ }^{1}$ M.Sc. Student, Department of Mechanical Engineering, Faculty of Engineering, \\ University of Kufa, Al-Najaf, Iraq, Email: souadjabbar94@gmail.com \\ ${ }^{2}$ Prof., KCASE, Department of Mechanical Engineering, Faculty of Engineering, \\ University of Kufa, Al-Najaf, Iraq, Email: luays.alansari@uokufa.edu.iq \\ ${ }^{3}$ Asst. Prof., KCASE, Department of Mechanical Engineering, Faculty of Engineering, \\ University of Kufa, Al-Najaf, Iraq, Email: ahmedn.alusseini@uokufa.edu.iq; Visiting \\ Researcher, Department of Mechanical, Aerospace and Civil Engineering, University of \\ Manchester, Manchester, UK, Email: ahmed.alhulsseny@manchester.ac.uk

\section{${ }^{4}$ Senior Lecturer, Department of Mechanical, Aerospace and Civil Engineering,} \\ University of Manchester, Manchester, UK, Email: a.g.nasser@manchester.ac.ulk
}

\begin{abstract}
In this paper, the elasto-hydrodynamic (EHD) performance of partial journal bearings has been studied. A numerical analysis has been conducted using the ANSYS Workbench (17.2) platform to investigate the performance of partial journal bearings. The lubricant used is considered Newtonian and incompressible fluid that flows steadily under laminar conditions, while the bearing material is assumed to be elastic, isotropic with smooth surface conditions. In the current FSI analysis, the lubricant flow has been predicted according to the finite_volume method, while the finite element method has been adopted to compute the deformation and stress in the bearing surface. A wide range of operating and design conditions have been considered including the eccentricity ratio $(0.1 \leq \varepsilon \leq 0.82)$, and arc bearing angle bearing $\left(90^{\circ} \leq \theta \leq 180^{\circ}\right)$, while the values of bearing length to diameter ratio (L /D) and rotation speed (N) have been fixed at=0.77 and 1500r.p.m, respectively. The hydrodynamic pressure, performance characteristic of journal bearing, stress, and deformation have all been computed. It was found that the arc bearing angle and eccentricity ratio has a clear effect on the elastohydrodynamic properties of the partial bearings especially at high values of them.
\end{abstract}

KEYWORDS: Partial Bearing; CFD Analysis; Fluid-Solid Interaction; Pressure; Deformation; Stress. 


\section{INTRODUCTION}

Partial journal bearing is one of the common types of hydrodynamic journal bearings. It is widely used in industrial and daily life applications including rotary kilns, cement mills, and many other rotating types of machinery due to its lower power loss. It consists mainly of three main parts; the fixed part (bearing), running part (journal), and fluid layer (lubricant) between the two parts (bearing and journal). The lubricant is used to reduce wear, friction, and temperature generated due to friction.

(Yu and Szeri., 1975) studied the effect of the geometric parameters [pad angle $(\theta)$, bearing length to diameter ratio $(\mathrm{L} / \mathrm{D})$, clearance to radius ratio $(\mathrm{C} / \mathrm{R})$, eccentricity ratio $(\varepsilon)$ and radius ratio $\left(R_{o} / R_{i}\right)$ ] on partial bearing performance by solving both the momentum and the energy equations in laminar flow regime and taking the heat conduction into consideration as well. The mentioned equations are solved numerically by iteration method where the isothermal solution shows dependence on geometric parameters such as the pad angle or the aspect ratio. The thermo-hydrodynamic solution for a constant eccentricity shows, on the other hand, less dependence on geometric parameters, where increasing bearing size and/or shaft speed causes an increase in temperature rise and a reduction in bearing specific load. Then, A thermohydrodynamic (THD) lubrication model was presented by (Suganami and Szeri., 1979) for both laminar and turbulent flow regimes. A thermo- hydrodynamic (THD) model proposed was used to a partial journal bearing of 80 degree arc, where a central load was applied for length diameter (L/D) ratio equals to 0.75 while clearance to radius $(\mathrm{C} / \mathrm{R})$ ratio equal to 0.002 . Thermal effects were found to reduction load carrying capacity for each investigated case. This reduction was found to be modest at eccentricities is small. For example, low rates of heat generation, but in levels greater than eccentric it becomes significant. Moreover, it was observed that for a specific load is low, the eccentricity ratio in turbulent bearing is appreciably lower than it is for a laminar bearing. This contradiction was seen to disappear for higher specific loads, where pressure is considerably increased.

Malik et al., (1981) studied numerically the impact of tangential velocity-slip of thin film at the interface -area and the porous medium on the static / dynamic characteristics for a central- load 120 degree porous journal- bearing have a unity length to diameter ratio (L/D) and for an extensive range of permeable parameters such that the data acquired are very extensive for purposes of design. The results obtained indicated that the tangential velocity slip has large impact on stable and dynamic performance of the porous bearing. Considering of stable performance, the supported load, oil losses, and power loss in a slip excluded bearing are large than they are in a slip included bearing. 
Jain et al., (1982) achieved the impact of deformation in bearing on the load-carryingcapacity, attitude angle, frication - coefficient and lubricant flow in partial arc bearings $60^{\circ}$ and $120^{\circ}$. The conjugated Reynolds equation that meets the pressure field of a liquid thickness and the three dimensional (3D) equations of elastic that control the bearing deformations liner are simultaneously solved using FEM (Finite Element Method). Where found the reduction of load carrying in 60 degree is less than it is in 120 degree at same eccentricity ratio (0.7). Also, load carrying capacity of $60^{\circ}$ with same eccentricity ratio (0.7) and deformation coefficient $(\Psi=0.005)$ was approximately $40 \%$ smaller than it was for a rigid bearing $(\Psi=0)$. Jain et al., (1983) examined the elastic deformation of the bearing liner by inspecting the static /dynamic performance characteristics of a central -bearing (120) degree with an eccentric rate about 0.8 and mean Reynolds number about 7500. The Fem (Finite -element -method) was using, the distribution of pressure in the liquid film thickness and the elastic deformation in the casing were calculated by repeatedly solving Reynolds equation and 3D elastic equations. The bearing performance characteristics were measured for various values of deformation coefficient, which is a measure of the flexibilities of the bearing wall. Also, some results were recorded for laminar / turbulent flow conditions considering the viscosity is a variable (function to the pressure). Khonsari et al., (1996) predicted the thermo- hydrodynamic phenomenon in journal bearings, where two different thermal boundary conditions were considered and compared. The first was an isothermal journal bearing with adiabatic inner bush surface, while the second was a full thermo- hydrodynamic solution of a journal bearing. The results computed were used to develop thermo- hydrodynamic design charts applicable to journal bearing systems. In these charts, the dimensionless values of maximum bearing temperature and shaft surface temperature can be estimated depending on two parameters called the $1^{\text {st }}$ and $2^{\text {nd }}$ temperature-rise parameters, $K_{1}$ and $K_{2}$, respectively. The first parameter is a function to the lubricant properties, bearing geometry, radius of journal and clearance, while the other is a function to the linear velocity of the shaft.

Dobrica et al., (2006) examined a specific numerical model viable on partial journal bearing operating in mixed lubrication region. Simulations were execute for various models of roughness and eccentric ratio (0.8-1.08). The critical obtained results for hard and flexible rough surface of bearing compared with the results presented by Patir and Cheng, (1987) as well as smooth surface model data. It was apparent that surface roughness affected all performance characteristics of bearing including fluid film thickness, angle of attitude, and friction- torque. However, the roughness effect seems has largely dependent on the direction of roughness. Compared to smooth surfaces and by used hypothesis rigid pad (HD) model, it showed the 
largest effect of roughness resulting in an increase of (30\%) in the minimum mean film thickness, and more of (54\%) in friction torque. Roughness of isotropic properties had smaller effect but still had the large impact on performance of bearing. On other hand, the longitudinal -roughness seemed had affect only on friction- torque. When the deformation is allowed in pad response to the hydrodynamic- pressure model, it was observed that the overall effect of roughness is greatly diminished. Patir and Cheng model seemed to correctly predict the directions posed by various roughness types unless for the attitude- angle.

The elasto-hydrodynamic lubricant analysis (EHL) for a $60^{\circ}$ radial partial bearing was analyzed by Bhat et al., (2007) using the CFD (Computing-Fluid-Dynamics) with CSD (ComputingStructural- Dynamics) .This combined field analysis employed the calibers of the ANSYS / FLOTRAN commercially available finite element program with fluid -solid interaction (FSI) technology. The pressure was found by using computational fluid dynamic considering that the flow was laminar. The distribution of deformations and stresses on the bush is obtained due to force of pressure by using the method of finite element satisfying the boundary conditions.

The circumferential scratches which appear in the inner bearing surface was studied analytically by Dobrica and Fillon, (2008) and explained their effect on the thermo-hydrodynamic performance- characteristics such as minimum film thickness $\left(\mathrm{h}_{\min }\right)$, maximum pressure $\left(\mathrm{P}_{\max }\right)$, mean oil film temperature( $\left.\mathrm{T}_{\text {mean }}\right)$, and friction torque. The effects predicted were especially important for central - deep scratches. It seems that the most important parameter for measuring the intensity of scratching is the worn out area. When the scratches spread over the inner bearing surface, they was likely to result to the bearing destruction, even if it is comparatively slim and represents small section from the total -width of bearing. The other important parameter is the depth of scratch, as deep scratches were found to reduce the local pressure about to surrounding pressure. It was also noticed that density of scratch appears to be only important for scratches surface $\left[\mathrm{h}_{\mathrm{s}}<C / 4\right]$, or when a few area of bearing is destruction. Finally, smaller wear impacts are found when scratches are moved toward the bearings edges.

Abass et al., (2010) examined the performance of partial journal bearings based on steady state thermo-hydrodynamic model (THD) for partial journal bearings. The generalized Reynold's equation, the energy equation in oil- film and the equation of heat transfer in pad and shaft were solved simultaneously. The shaft temperature has been found a large influence on the bearing performance, where both oil and bush temperature increase with the increase of shaft temperature while the oil film thickness decreases. 
An isothermal hydrodynamic analysis was conducted numerically by Dobrica and Fillon., (2012) to evaluate the overall performance degradation happen in scratched journal bearings. The scratches severity was measured the usage four parameters, namely the scratch depth, the scratched extent area, the scratches density and the scratched location. In order to evaluate overall bearing performance degradation, several working parameters were calculated minimum oil film thickness $\left(h_{\text {min }}\right)$, mean oil temperature $\left(T_{\text {mean }}\right)$ and maximum hydrodynamic pressure (PMAX). Most of the examined parameters seem to have an extensive impact on bearing performance, the deeper / greater severe scratches, the extra bearing performance. In general, the scratch depth seems to be the most selective parameter if the scratch depth is solely small in relation to the film thickness $\left(h_{s}=\mathrm{C} / 8\right)$ the bearing overall performance is solely barely affected. On the contrary, if the scratches reach depths equal to clearance $\left(h_{s}=\mathrm{C}\right), \quad$ the performance is severely affected, that means that performance degradation can be minimal in a low-load bearing and adverse in a high-load bearing which similarly complicates the contrast from scratch effects.

Liang et al., (2016) investigated the hydrodynamic -performance of lubrication a partial textured- sliding journal bearing utilizing CFD ADINA program, and the limit requirement of the phase change has been applied to the fluid field. It was found that texture found at entrance area of the lubricant that the bearing performance can be improved. Otherwise, bearing performance is reduced because the texture found at the area of a maximum pressure. While the texture found at the outlet area of lubricant have two various consequences: a portion of the texture found inside the divergent area of oil film improves the load carrying capacity, but the portion outside the divergent area makes the load carrying capacity decrease.

Various thermo - hydrodynamic partial journal bearings and operating conditions have been briefly reviewed according to the status of bearing inner surface whether it was smooth or not. The current project aims to study the effect of arc bearing angle $(\theta)$ at different eccentricity $\operatorname{ratio}(\varepsilon)$ on the elasto-hydrodynamic performance of a partial journal bearings where the inner surface of bearing is smooth under static conditions, various geometric shapes and operating conditions.

\section{MATHEMATICAL MODEL}

The mathematical model in this study is divided into two parts. The first is the fluid film layer (lubricant), while the other is the solid structural (bearing or Fixed pad), as shown in Fig. 1. 


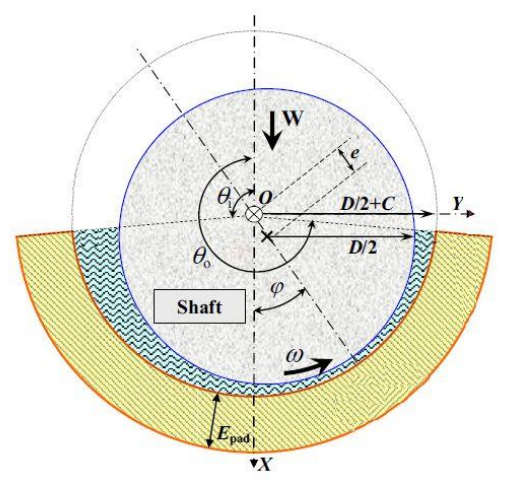

Fig. 1. Partial journal bearing (Dobrica and Fillon, 2012).

Thus, the partial differential equations governing the conservation of mass and momentum for the fluid film layer are as follows (Versteeg and Malalasekera, 2007):

$$
\begin{aligned}
& \frac{\partial u}{\partial x}+\frac{\partial v}{\partial y}+\frac{\partial w}{\partial z}=0 \\
& \rho_{f}\left(u \frac{\partial u}{\partial x}+v \frac{\partial u}{\partial y}+w \frac{\partial u}{\partial z}\right)=-\frac{\partial p}{\partial x}+\mu\left(\frac{\partial^{2} u}{\partial x^{2}}+\frac{\partial^{2} u}{\partial y^{2}}+\frac{\partial^{2} u}{\partial z^{2}}\right) \\
& \rho_{f}\left(\mathrm{u} \frac{\partial \mathrm{v}}{\partial \mathrm{x}}+\mathrm{v} \frac{\partial \mathrm{v}}{\partial \mathrm{y}}+\mathrm{w} \frac{\partial \mathrm{v}}{\partial \mathrm{z}}\right)=-\frac{\partial \mathrm{p}}{\partial \mathrm{y}}+\mu\left(\frac{\partial^{2} \mathrm{v}}{\partial \mathrm{x}^{2}}+\frac{\partial^{2} \mathrm{v}}{\partial \mathrm{y}^{2}}+\frac{\partial^{2} \mathrm{v}}{\partial \mathrm{z}^{2}}\right) \\
& \rho_{f}\left(\mathrm{u} \frac{\partial \mathrm{w}}{\partial \mathrm{x}}+\mathrm{v} \frac{\partial \mathrm{w}}{\partial \mathrm{y}}+\mathrm{w} \frac{\partial \mathrm{w}}{\partial \mathrm{z}}\right)=-\frac{\partial \mathrm{p}}{\partial \mathrm{z}}+\mu\left(\frac{\partial^{2} w}{\partial x^{2}}+\frac{\partial^{2} w}{\partial y^{2}}+\frac{\partial^{2} w}{\partial z^{2}}\right)
\end{aligned}
$$

Where $\rho_{f}, p, u, v, w$ stand for the lubricant density, pressure, $x, y$, and $z$ - velocity component, respectively. While $\mu$ stands for the lubricant dynamic viscosity.

For solid domain, the partial differential equations governing can be described using the second law of motion (Liu, H. et al. 2010):

$$
\rho_{s} \ddot{\delta}=\nabla \cdot \sigma_{s}+\mathrm{f}_{\mathrm{s}}
$$

As the film flow is surrounded by solid walls, no-slip occurs on each of the journal and bearing surfaces. This implies that the lubricant particles in the vicinity of the rotating journal always have zero velocity relative to the rotating shaft to maintain the non-slip condition. Moreover, the condition at the sidewalls bounding the film field is assumed to be at atmospheric state, i.e. zero gauge pressure. Thus, the coherent boundary conditions used are:

$$
\left.\begin{array}{ccc}
\text { at } & z=\mp \frac{L}{2}: & p=p_{a t m}=0 \\
\text { at } & r=R_{j}: & u_{\theta}=\omega R_{j}, u_{r}=u_{z}=0 \\
\text { at } \quad r=R_{b i}: & u_{\theta}=u_{r}=u_{z}=0
\end{array}\right\}
$$


On the other hand, the solid bearing is exposed to an internal pressure load resulting from the lubricant flow field, while the external wall is considered to be fixed. Furthermore, the side boundaries are maintained free-loaded. Thus, the coherent boundary conditions used are:

$$
\left.\begin{array}{llc}
\text { at } & r=R_{b i}: & F=p(r, \theta) d A \\
\text { at } & r=R_{b o}: & \delta=0 \\
\text { at } & z= \pm \frac{L}{2}: & F=0
\end{array}\right\}
$$

\section{NUMERICAL ANALYSIS}

In the current FSI analysis, the partitioned one-way coupling is employed, where the fluid film pressure are firstly computed using the well-known ANSYS Fluent CFD commercial code, and then, transferred to the ANSYS Static Structure solid solver to compute the deformation and stress resulted in the solid bearing zone. Both fluid and solid zones have been discrctized into a number of hexahedral elements, as illustrated in Fig. 2. Solution method used for CFD simulation is based on the second-order upwind differencing scheme, where the discretised equations for the lubricant flow field have been solved iteratively according to the SIMPLE algorithm (Versteeg and Malalasekera, 2007).

The grid dependency was checked for three sets of film mesh to examine the sensitivity of the results computed to the number of grid divisions along each of the physical coordinates, i.e. radial $n i$, circumferential $n j$, and axial $n k$. In general, it has been observed that the number of divisions along the radial direction $n i$ dominates the accuracy of the solution obtained unlike the number of divisions along the other two directions, i.e. $n j$ or $n k$, which have no noticeable impact. As shown in Table 1, increasing the grid divisions along the radial coordinate improves the results accuracy significantly until the error becomes quite marginal between $n i=9 \&$ 10.Thus, using only nine divisions across the clearance space sounds quite reasonable. As preceded, the increase in the grid divisions along either the circumferential or axial coordinate results in no obvious change in the maximum pressure applied on the bearing surface. However, the circumference and axial length have been respectively divided into 400and 600 elements to avoid having extremely slim elements, or in other words, keeping reasonable values of aspect ratio. Therefore, the selected grid dimensions results in a reasonable mesh quality. For fluid flow zone, the maximum aspect ratio ranges from 9 to 57 , minimum orthogonal quality ranges from 0.68 to 0.99 , and maximum ortho-skew ranges from0.0003 to 0.2. For the bearing zone, the aspect ratio equals to 1.20 with minimum orthogonal of 0.999 and maximum ortho-skew of $4.44 * 10^{-3}$. Accordingly, a grid size of $(n i=9, n j=400, n k=600)$ is considered for all the 
simulations to be carried out in the current investigation and for all arc angles of partial journal bearing at each eccentricity ratios.

Table 1. Grid dependence at $\varepsilon=0.1, \mathrm{~L} / \mathrm{D}=0.77, \mathrm{~N}=1500$ and $\theta=170 \mathrm{Deg}$.

\begin{tabular}{ccc}
\hline $\boldsymbol{n}_{\boldsymbol{i}}$ & Number of Element $\left(\boldsymbol{n}_{\boldsymbol{i}} \times \boldsymbol{n}_{\boldsymbol{j}} \times \boldsymbol{n}_{\boldsymbol{k}}\right)$ & Max. Pressure(Pas) \\
\hline $\mathbf{2}$ & 480000 & 75200 \\
$\mathbf{3}$ & 720000 & 96600 \\
$\mathbf{4}$ & 960000 & 107000 \\
$\mathbf{5}$ & 1200000 & 113000 \\
$\mathbf{6}$ & 1440000 & 117000 \\
$\mathbf{7}$ & 1680000 & 119000 \\
$\mathbf{8}$ & 1920000 & 121000 \\
$\mathbf{9}$ & 2160000 & 122000 \\
$\mathbf{1 0}$ & 2400000 & 122000 \\
\hline
\end{tabular}

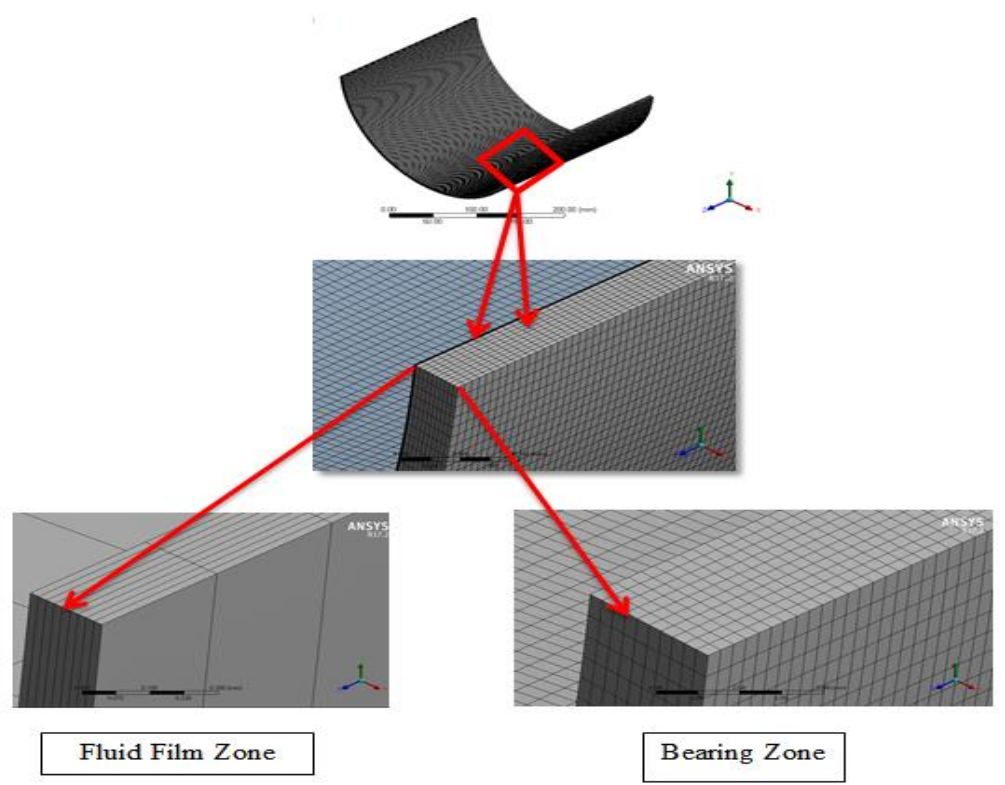

Fig. 2. Mesh generated for fluid film and bearing zones.

To overcome potential instability during the iterative solution, under-relaxation is applied to the solution of the lubricant flow domain, as detailed in Table 2.

Table 2. The under relaxation factors (URF) used in present study.

\begin{tabular}{cccc}
\hline Pressure & Density & Body Force & Momentum \\
\hline $0.1-0.3$ & 1 & 1 & $0.1-0.5$ \\
\hline
\end{tabular}


Any numerical study needs to be validated with another previous study. So, the currently simulated FSI data were compared with the numerical obtained data by (Dobrica and Fillon, 2012), where the pressure profile variation along the journal pad is, in general, in agreement with that presented by (Dobrica and Fillon,2012), as shown in Fig.3.

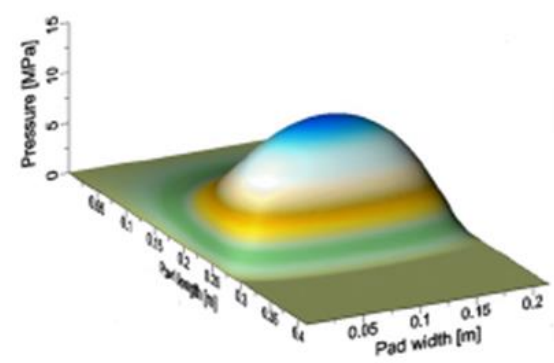

Dobrica and Fillon,2012

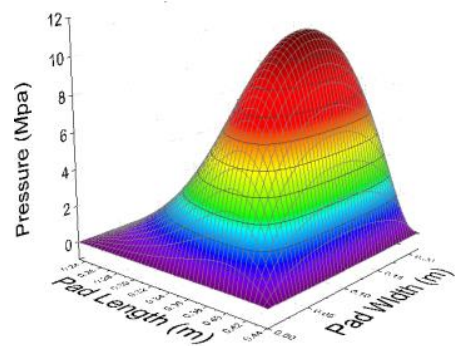

Present work

Fig. 3. A comparison between the pressure distribution obtained in the present work numerically with the corresponding data measured numerically by (Dobrica and Fillon, 2012)。

Overall, this comparison revealed the validity of the current computational simulation, where the maximum deviation was about $5 \%$, as shown in Table 3 .

Table 3. Maximum Deviation (Error)\%.

\begin{tabular}{lcc} 
Maximum Pressure $[\mathrm{MPa}]$ & Maximum Pressure[MPa] & $\begin{array}{c}\text { Maximum Deviation } \\
\text { (Error)\% }\end{array}$ \\
\hline
\end{tabular}

\section{RESULTS AND DISCUSSION}

The results obtained were calculated for a wide range of operating and design conditions have been considered including the eccentricity ratio $(0.1 \leq \varepsilon \leq 0.82)$ and arc bearing angle $\left(90^{\circ} \leq\right.$ $\theta \leq 180^{\circ}$ ), while the values of bearing length to diameter ratio $(L / D)$ and rotation speed $(N)$ have been fixed at 0.77 and $1500 \mathrm{rpm}$, respectively. The bearing geometry and the properties of the oil used in present work are detailed in Table 4.

\subsection{Effect of eccentricity ratio and arc bearing angle on fluid film pressure}

One of most design parameters influencing on the performance of partial journal bearing is the eccentricity ratio $(\varepsilon)$.Due to the load applied combined with shaft rotation inside the bearing, the journal is shifted downwards generating an eccentricity between the shaft and the bearing centers. In the present work, we has taken the effect of eccentricity ratio( $(\varepsilon)$ on the hydrodynamic 
pressure for various arc bearing angle, as shown in Fig.4 (left), when comparing the curves that the increase in the eccentricity ratio will increase the pressure. On the other hand, we has taken the effect of arc bearing angle $(\theta)$ on hydrodynamic pressure for varoius eccentricity ratio ,as shown in Fig.4 (right), also shown the increse in arc brearing angle will increse the hydrodynamic pressure due to the increase area of bearing surface which exerted to the appled load. A below set of Figures $(5,6,7)$ show the static pressure contours for various eccentricity ratio and arc bearing angle.

Table 4. Partial journal bearing dimensions and physical properties of ISO VG 32 oil (Dobrica and Fillon., 2012).

\begin{tabular}{ccc}
\hline Shaft radius & $R$ & $0.140(\mathrm{~m})$ \\
\hline Radial clearance & $C$ & $0.000224(\mathrm{~m})$ \\
\hline Bearing radius & $R_{B}$ & $0.140224(\mathrm{~m})$ \\
\hline Bearing length & $L$ & $0.215(\mathrm{~m})$ \\
\hline Bearing Thickness & $\mathrm{t}$ & $0.005(\mathrm{~m})$ \\
\hline Attitude angle & $\Psi$ & $0(\mathrm{Deg})$. \\
\hline Paisson's ratio & $v$ & $0.32(-)$ \\
\hline Modules of Elasticity & $\mathrm{E}$ & $127(\mathrm{GPa})$ \\
\hline Tensile yield strength & $\sigma_{Y}$ & $280(\mathrm{Mpa})$ \\
\hline Density of bearing material & $\rho_{b}$ & $8670\left(\mathrm{Kg} / \mathrm{m}^{3}\right)$ \\
\hline Lubricant(oil) Density & $\rho_{f}$ & $860\left(\mathrm{~kg} / \mathrm{m}^{3}\right)$ \\
\hline Lubricant (oil)Viscosity & $\mu$ & $0.03(\mathrm{~Pa} . \mathrm{s})$ \\
\hline
\end{tabular}
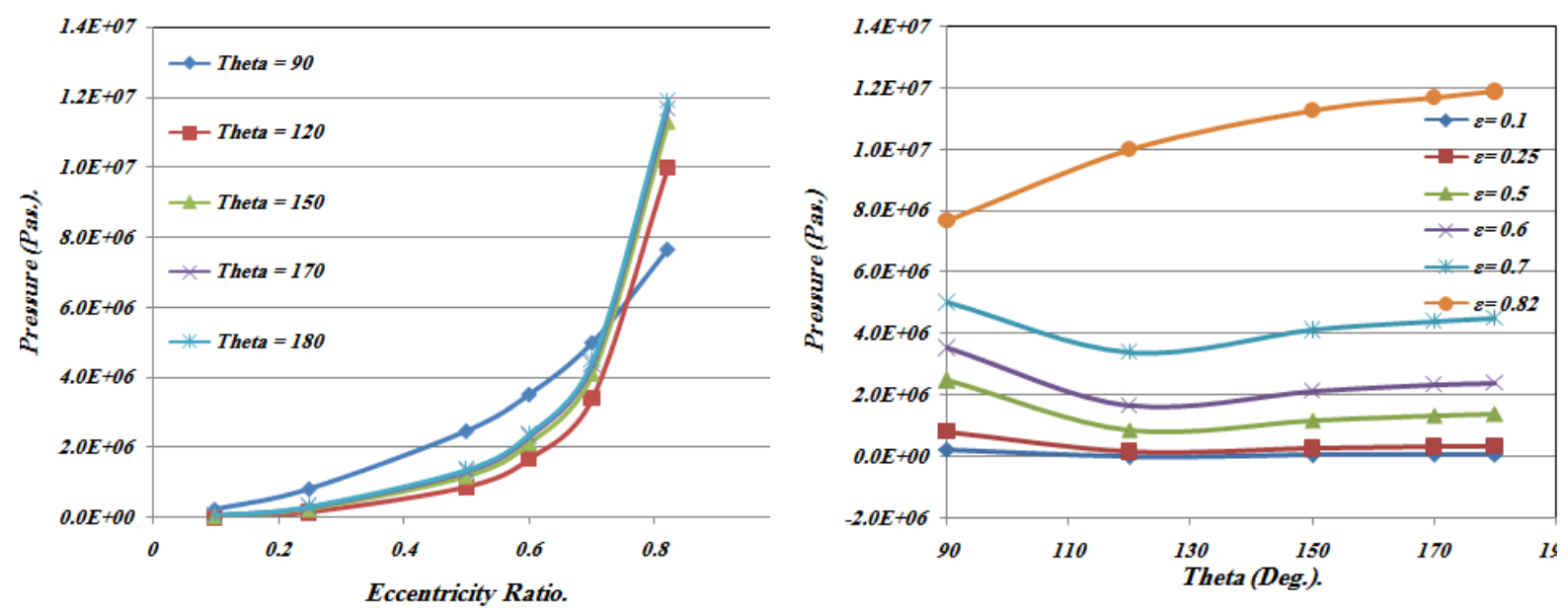

Fig. 4. Effect of eccentricity ratio (left) and arc bearing angle (right) on the fluid film pressure applied on bearing surface. 

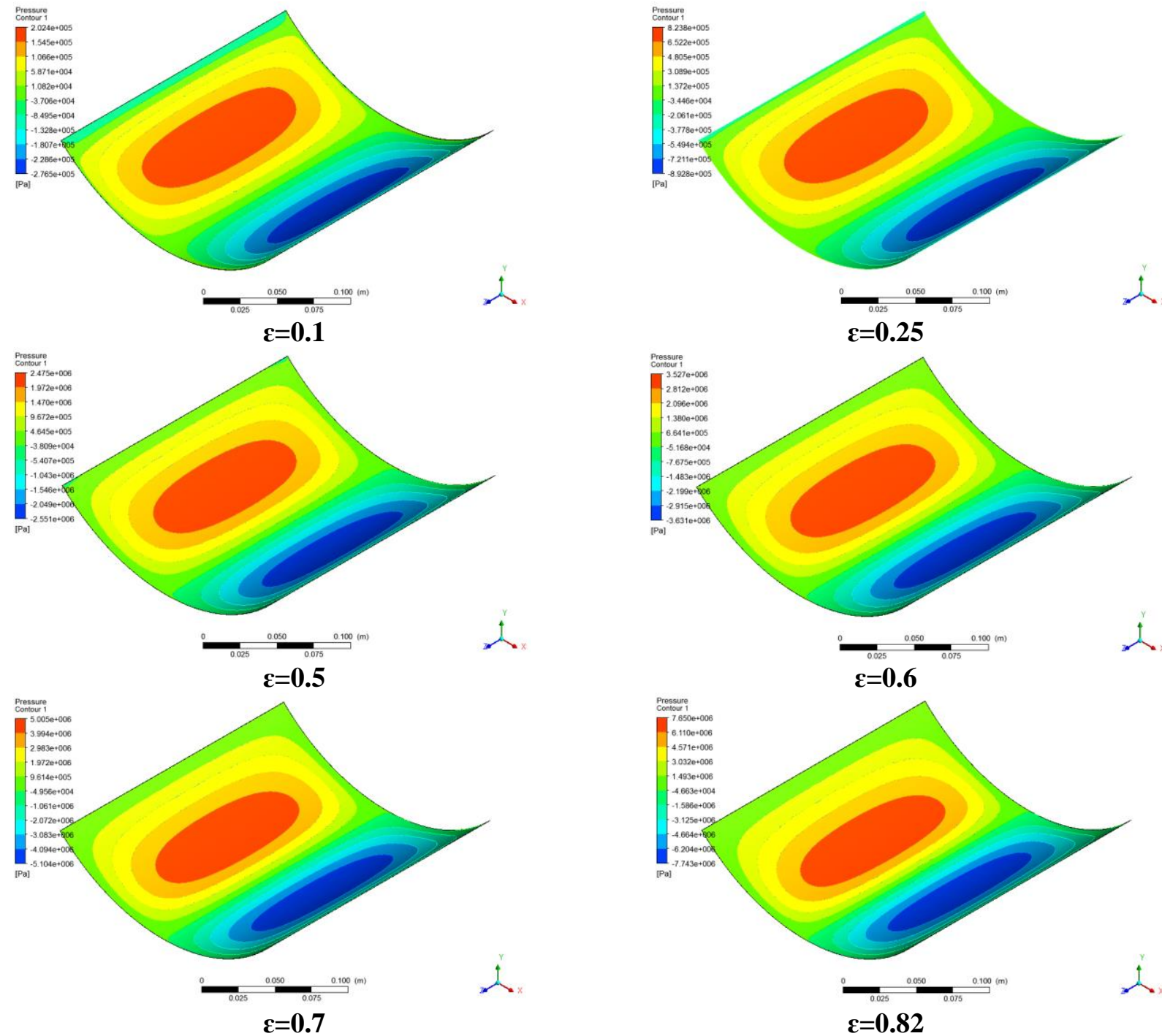

Fig .5. Effect of eccentricity ratio on film pressure applied on bearing surface for $90^{\circ}$ arc 

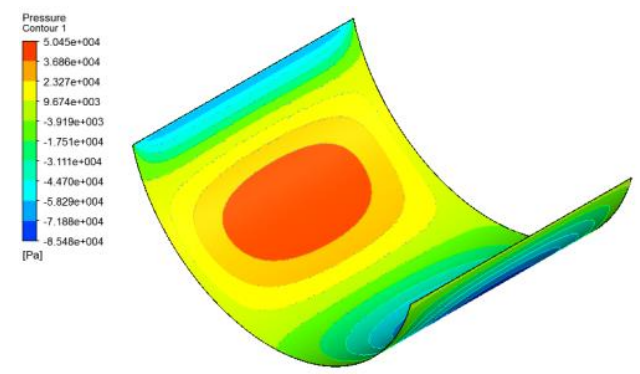

$-\frac{0.000}{0.0100}($ (m)
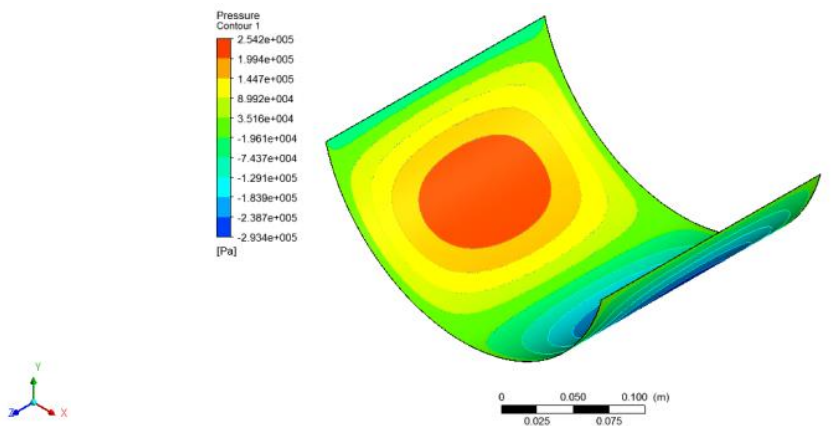

$\varepsilon=0.1$

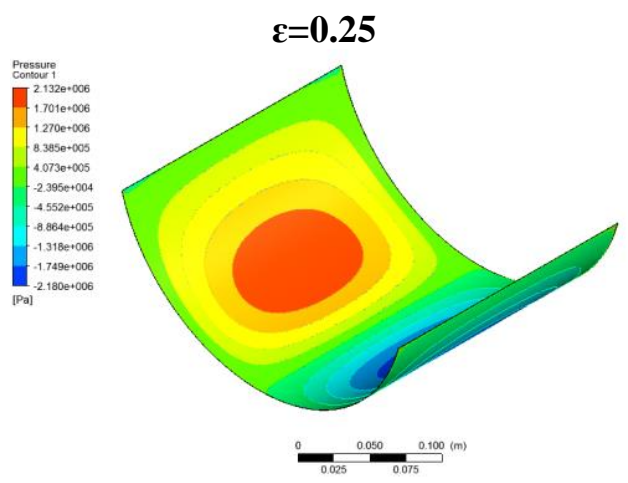

L.
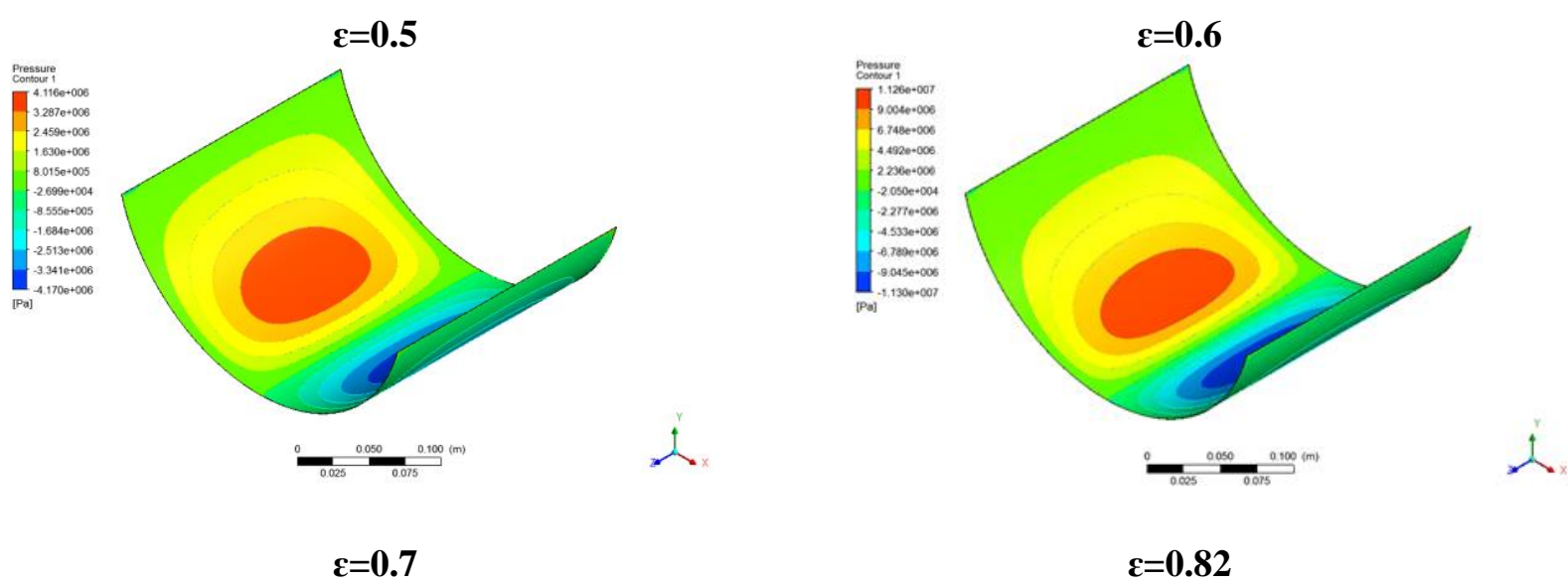

$\varepsilon=0.7$

$\varepsilon=0.82$

Fig .6. Effect of eccentricity ratio on film pressure applied on bearing surface for $150^{\circ}$ arc 

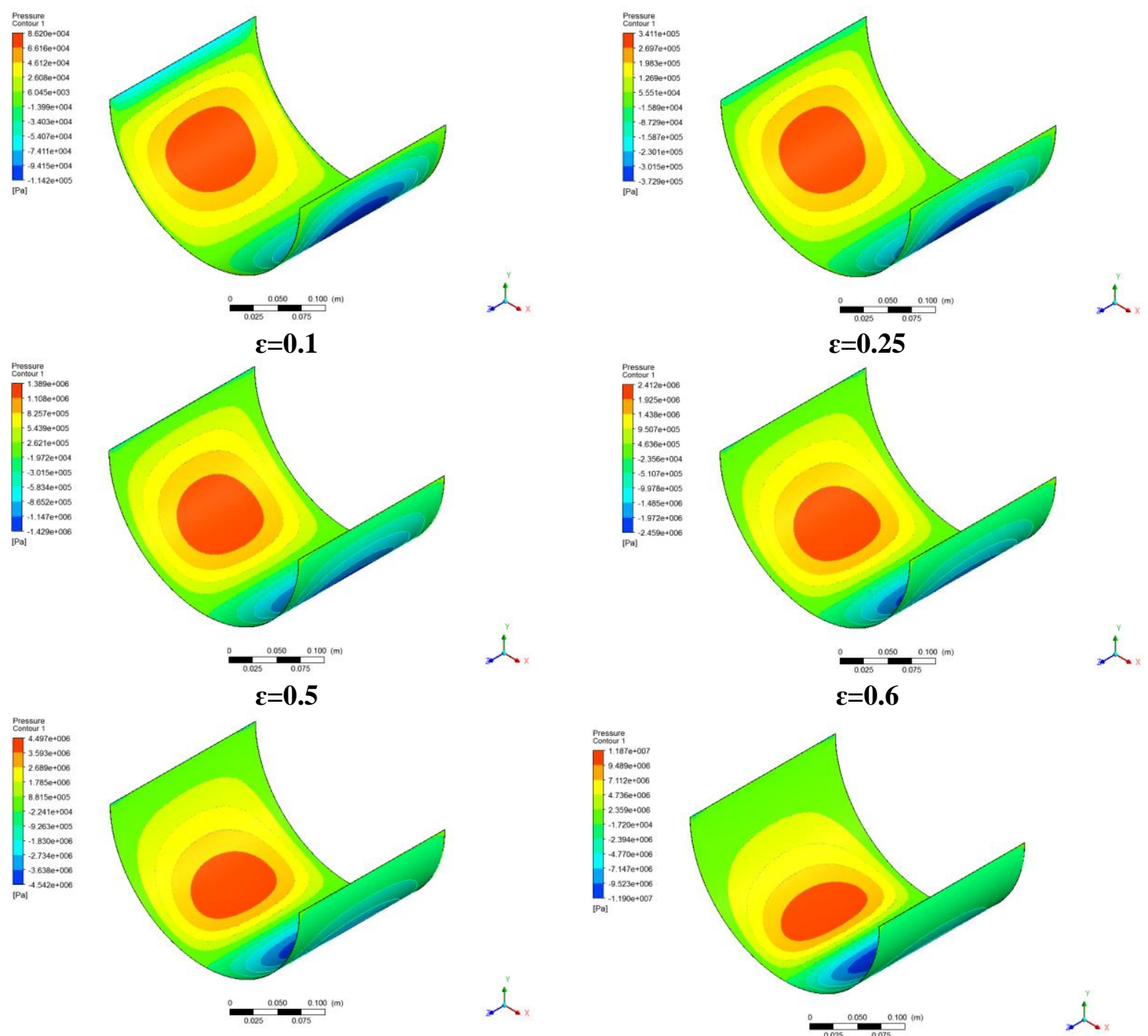

$\varepsilon=0.7$

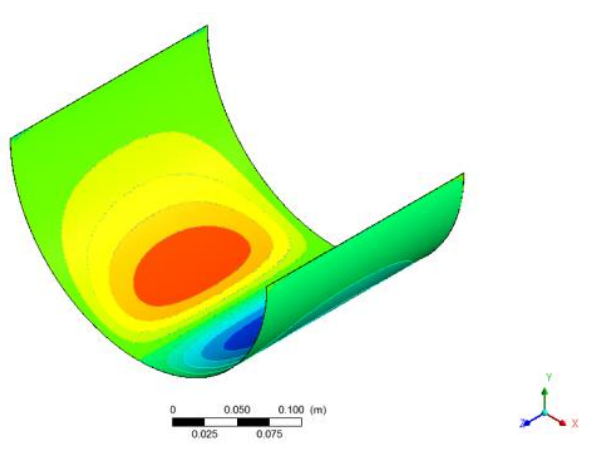

$\varepsilon=0.82$

Fig. 7. Effect of eccentricity ratio on film pressure applied on bearing surface for $180^{\circ}$ arc.

\subsection{Effect of eccentricity ratio and arc bearing angle on overall performance of partial journal bearing}

One of the most important parameter in select operating in journal bearing at specific conditions is the load applied on it ,where called the load carrying capacity which can be calculated from the double integration of the pressure compoents on journal surface $(W=$ $\left.\iint_{A_{j}} p(r, \theta) d A_{j}\right)$, Where found due to increase in pressure on inner bearing surface with the incresse of eccecntricity ratio and arc bearing angle, the load carrying capacity also increase, as shown in Fig. 8. 

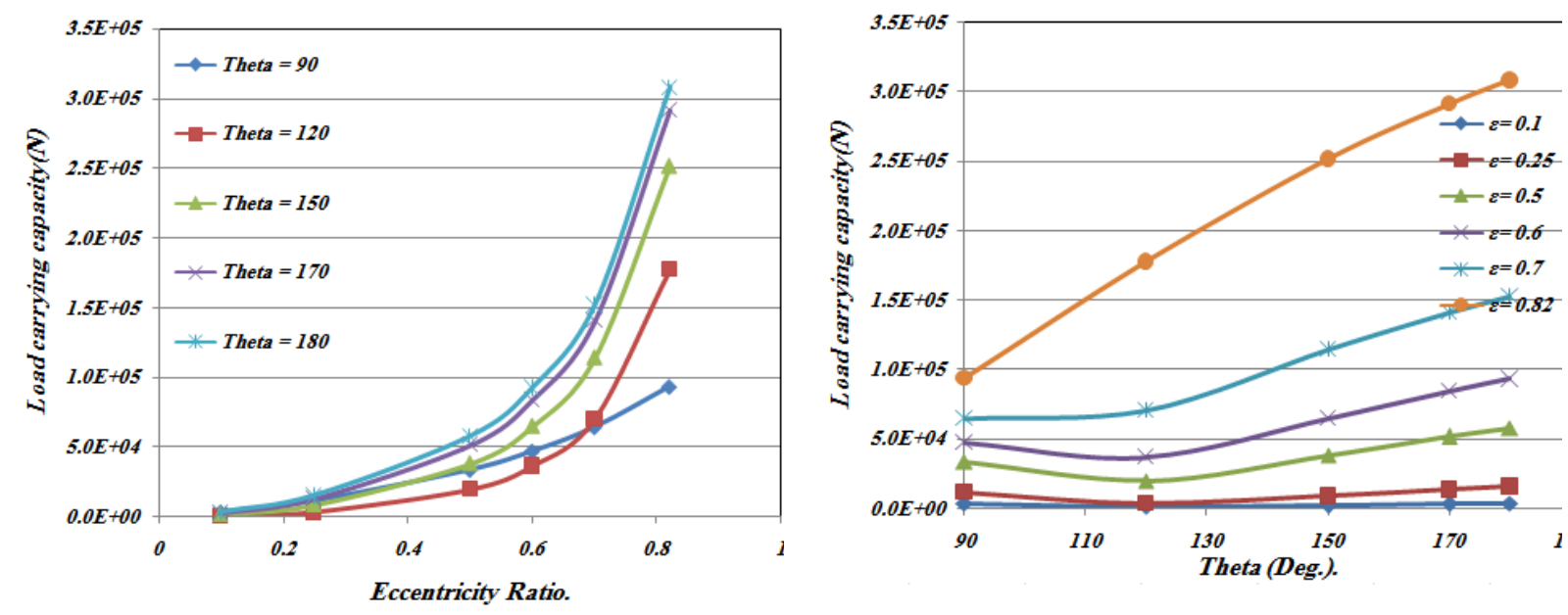

Fig. 8. Effect of eccentricity ratio (left) and arc bearing angle (right) on the load carrying capacity.

Sommerfeld number, which is defined as $\left(S_{n}=\frac{\mu_{i} U_{j} L\left(\frac{R_{j}}{c}\right)^{2}}{\pi W}\right)$, is a dimensionless quantity useful in bearings design. It involves the combined effects of oil viscosity, bearing dimensions, rotation speed, and the load applied. It has reverse proportional to load applied. So, Sommerfeld number decrease when load carrying capacity increase with the increase both the eccentricity ratio and arc bearing angle. As shown in Fig. 9.

The friction force, which is defined as $\left(F_{f_{i}}=\iint_{A_{i}} \tau_{i} d A_{i}\right)$, which is directly proportional to shear stress and rotation speed, where i stands for the surface where the friction force acts on, which is either the journal surface or the bearing surface. As the friction force acting on the journal surface represents the source of film rotational motion, its value is higher than it is on the inner surface of the bearing. The friction force increase when load carrying capacity increase with the increase both the eccentricity ratio and arc bearing angle. As shown in Fig. 10. Therefore, the coefficient of friction, wherever it is mentioned in the text, which represents the ratio of the friction force to the load applied, which is reverse proportional to load applied. The coefficient of friction increase when load carrying capacity increase with the increase both the eccentricity ratio and arc bearing angle. As shown in Fig. 11. 

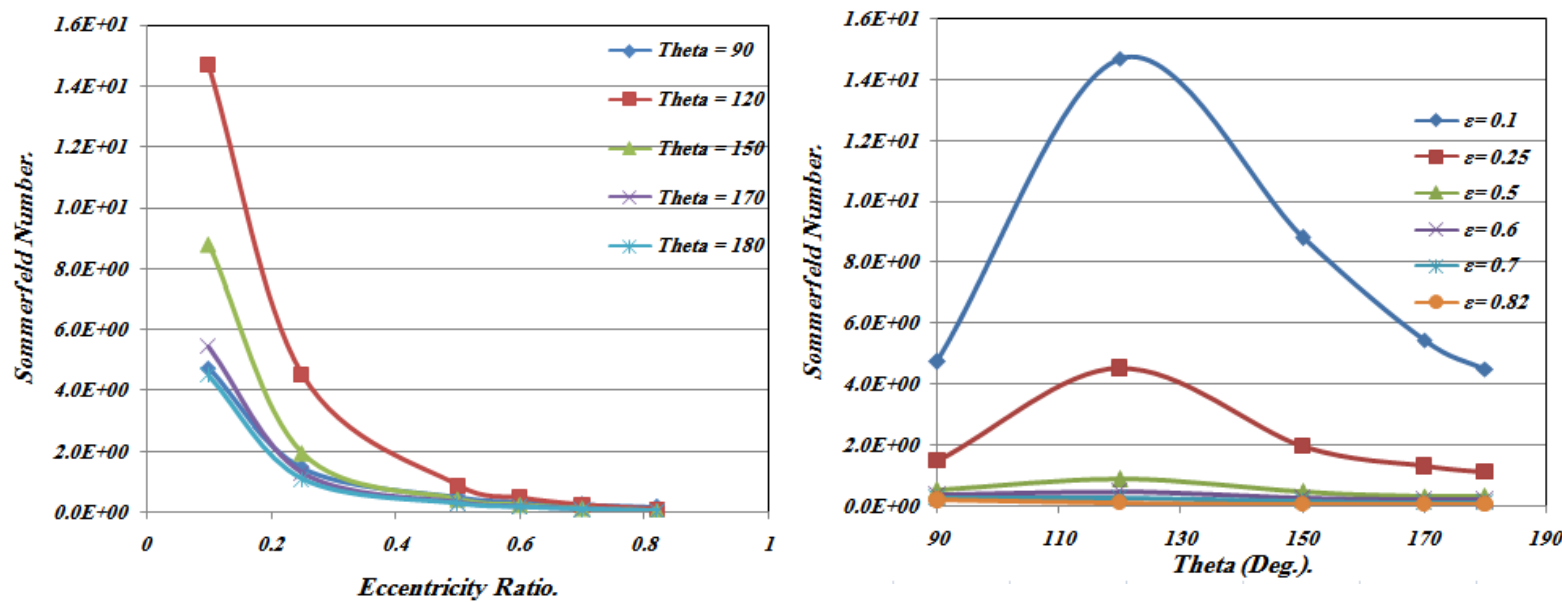

Fig. 9. Effect of eccentricity ratio (left) and arc bearing angle (right) on the Sommerfeld number.
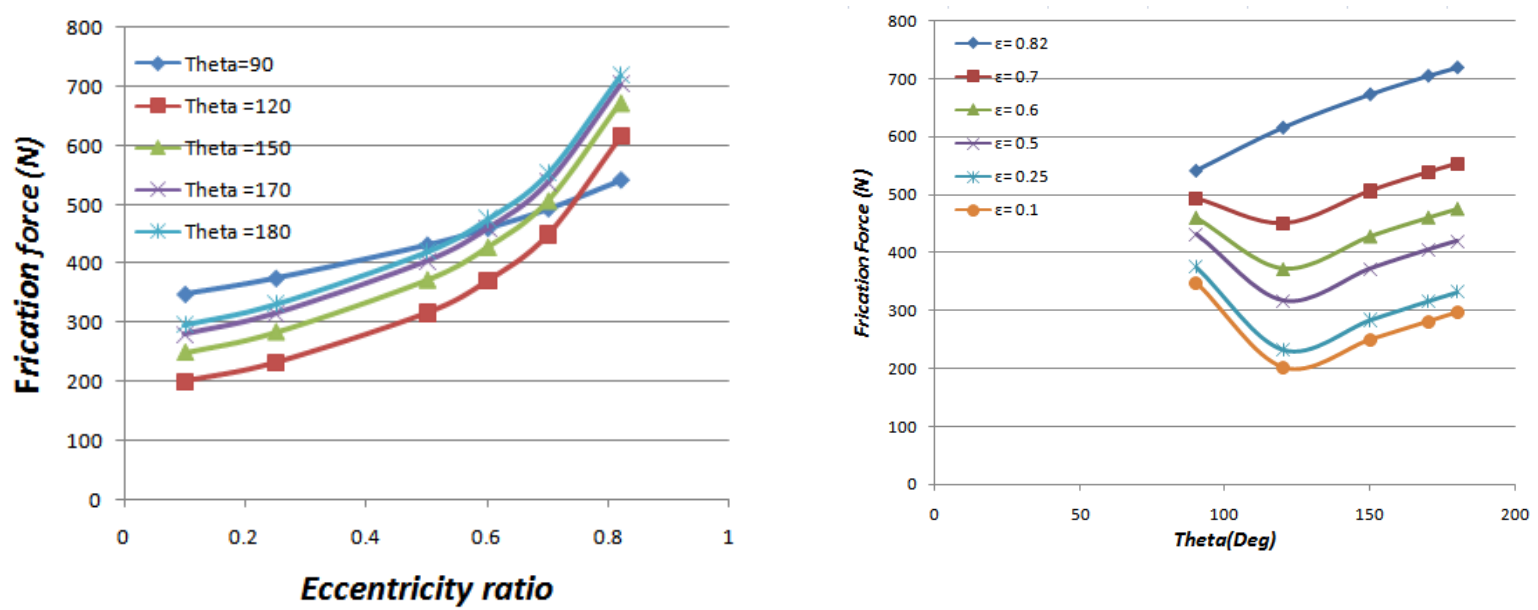

Fig. 10. Effect of eccentricity ratio (left) and arc bearing angle (right) on the friction force.
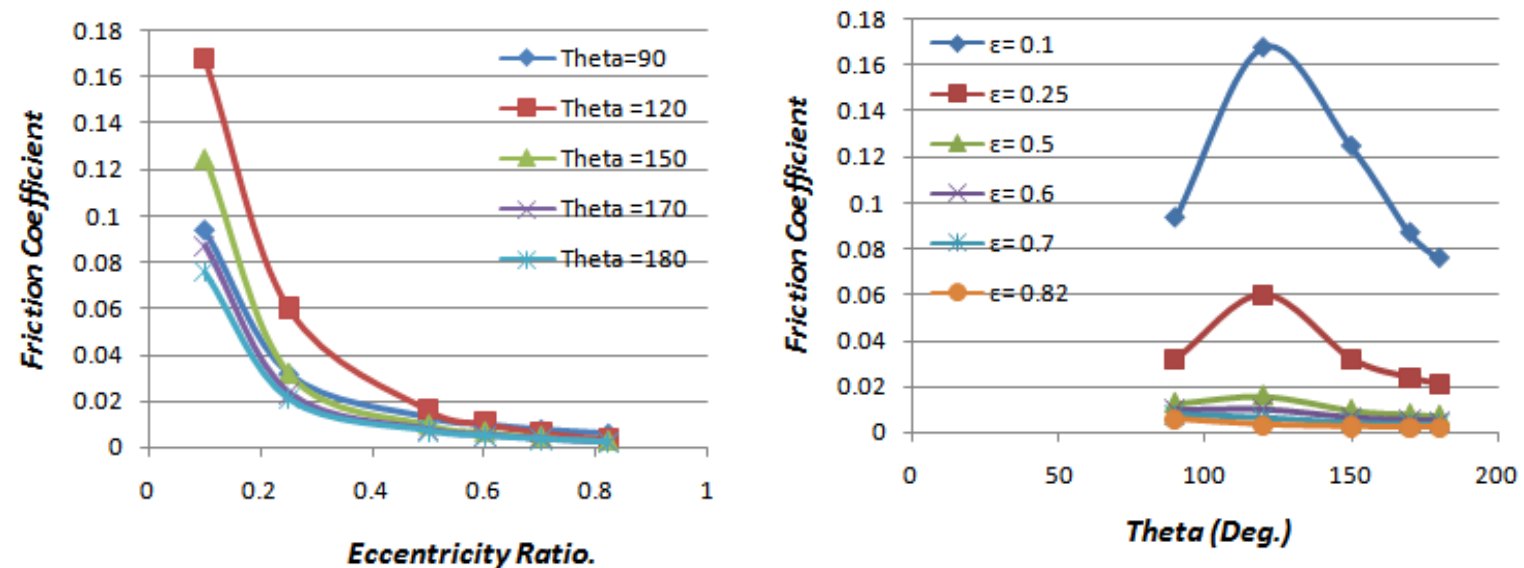

Fig. 11. Effect of eccentricity ratio (left) and arc bearing angle (right) on the friction coefficient. While the journal rotates inside the bearing, an amount of the energy to be transported is lost due to friction, power loss is directly proportional to each of the friction force and the rotation 
speed and defined as $\left(H=C_{f} W U_{j}\right)$. The power loss increases with the increase both the eccentricity ratio and arc bearing angle. As clearly demonstrated by Fig. 12.
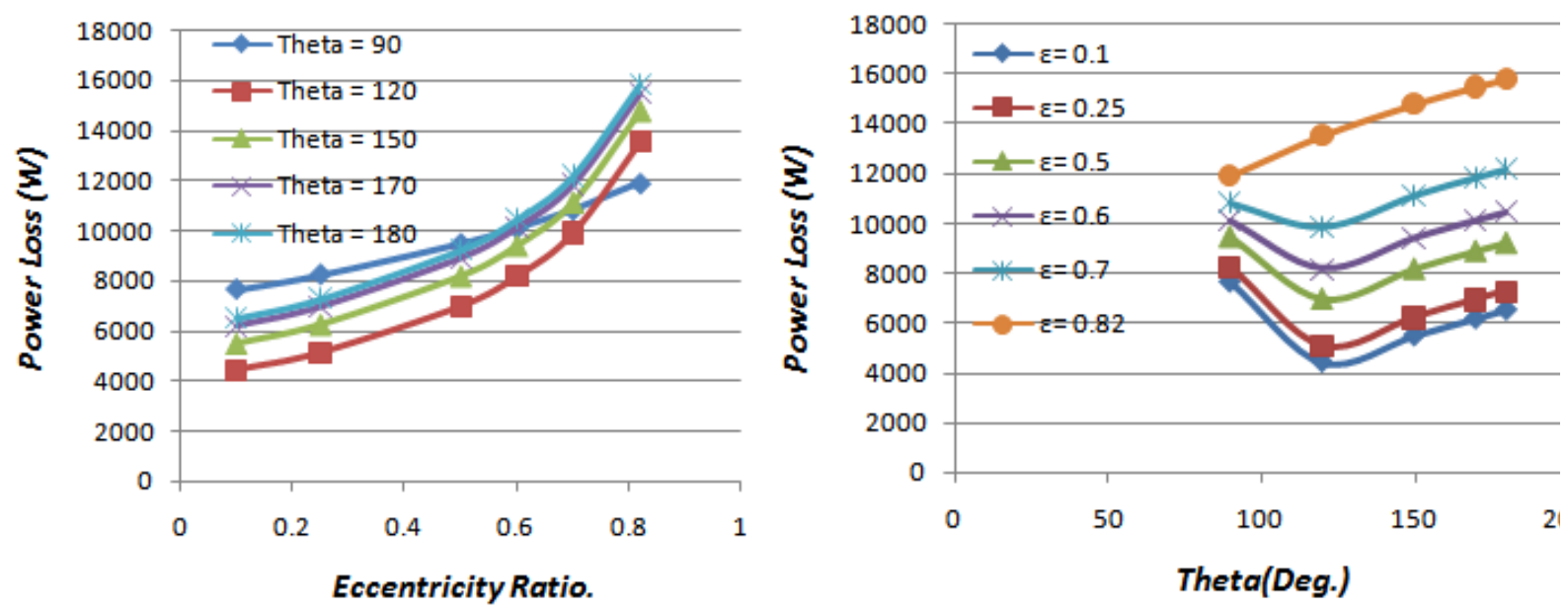

Fig. 12. Effect of eccentricity ratio (left) and arc bearing angle (right) on the power loss.

\subsection{Effect of eccentricity ratio and arc bearing angle on the elastic performance of partial journal bearings}

As a result of the pressure generated by the fluid film layer on the inner surface of bearing, the bearing is stressed. The bearing stress represented as a reflection to the pressure distribution along its inner surface, see Fig. 13, which explain the stress response to the change in eccentricity ratio (left)and arc bearing angle(right). On the left hand, the maximum stress is plotted in as a function to the eccentricity ratios for various arc bearing angle. Where the pressure increases with the eccentricity ratio, as mention previously, the stress generated on the inner surface of the bearing is increased as well. In general, shifting the journal downwards, or in other words increasing the eccentricity ratio, results in higher levels of the stress generated due to the augmentation of the lubricant pressure applied to the inner surface of the bearing. On other right hand, the maximum stress is plotted in as a function to the arc bearing angle for various eccentricity ratio which increased as well while increasing the arc bearing angle. A set of Figs. 14-16 show a stress contours for various eccentricity ratio and arc bearing angle. 

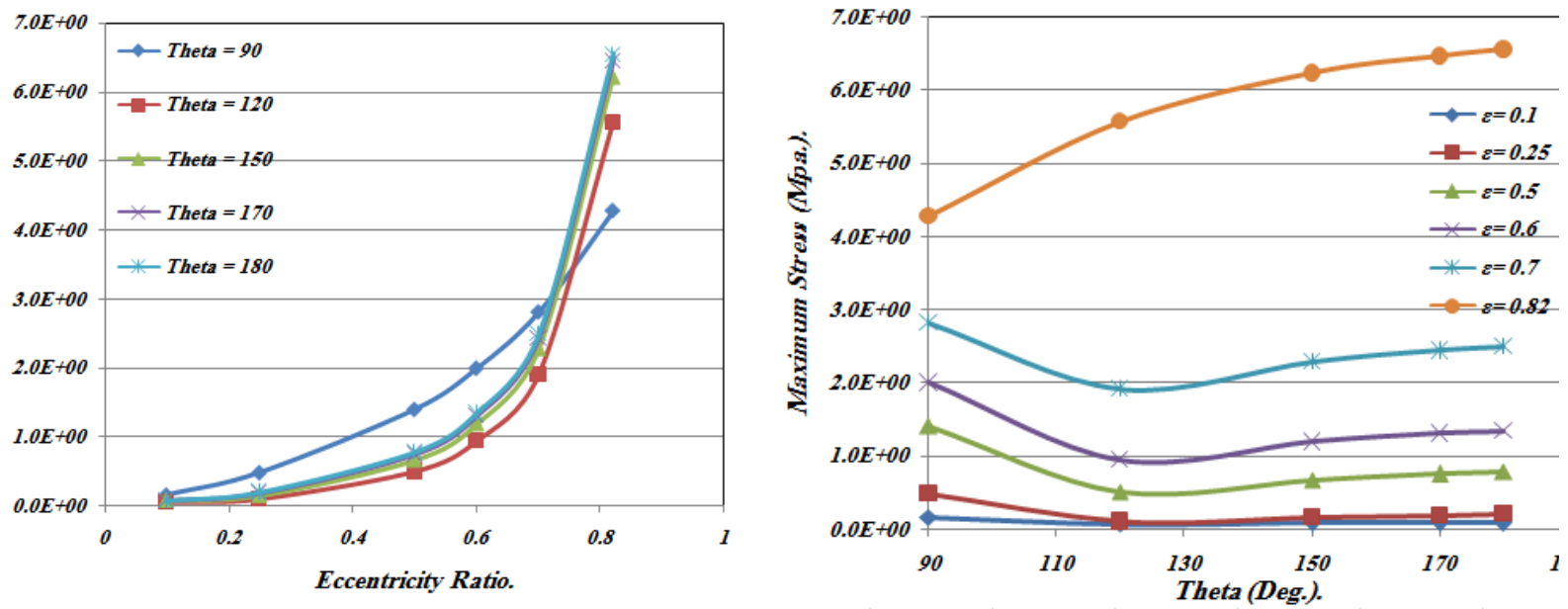

Fig. 13. Effect of eccentricity ratio (left) and arc bearing angle (right) on the maximum stress distribution on bearing inner surface.
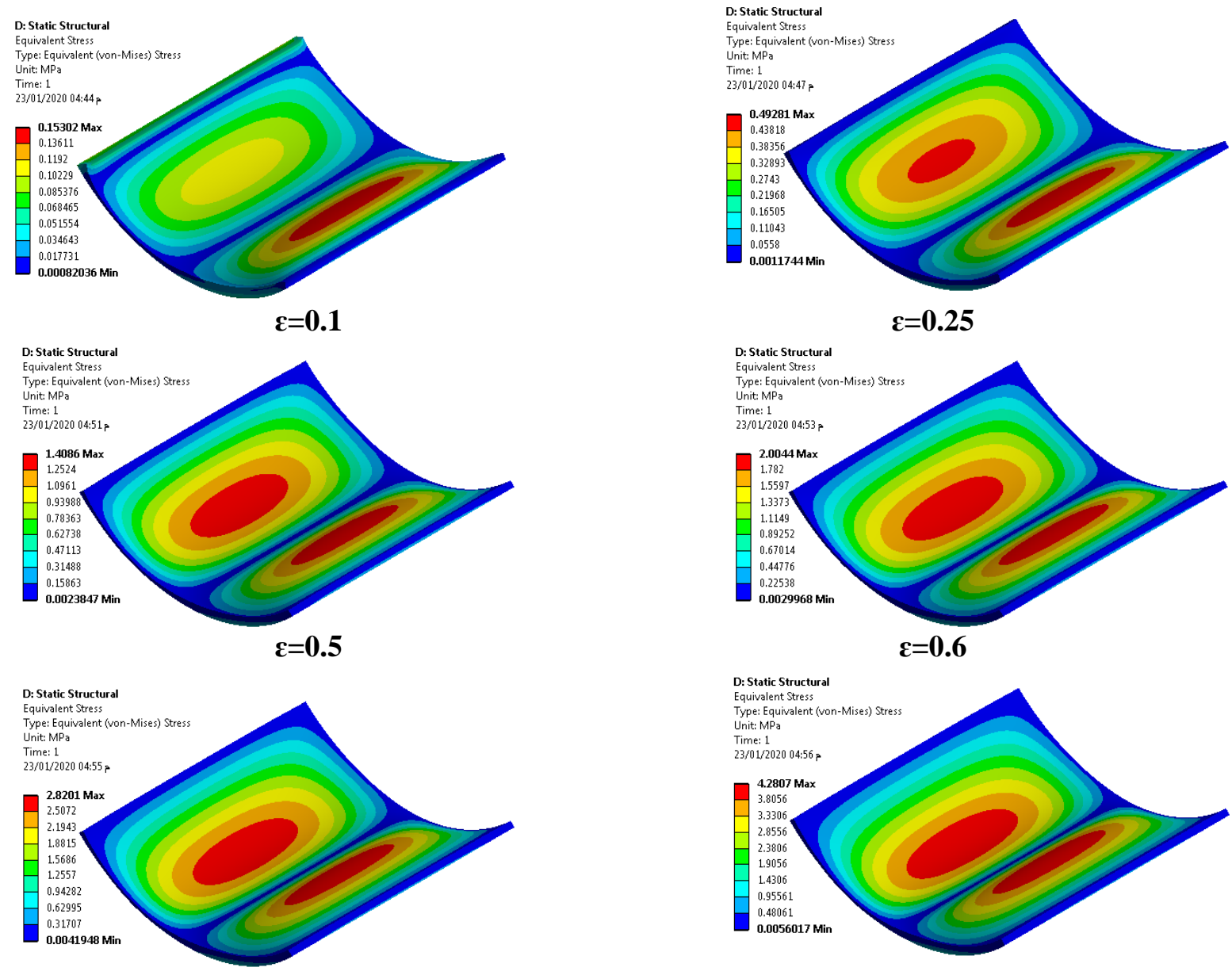

$\varepsilon=0.7$

$$
\varepsilon=0.82
$$

Fig. 14. Equivalent stress at various eccentricity ratios for $90^{\circ}$ arc bearing. 

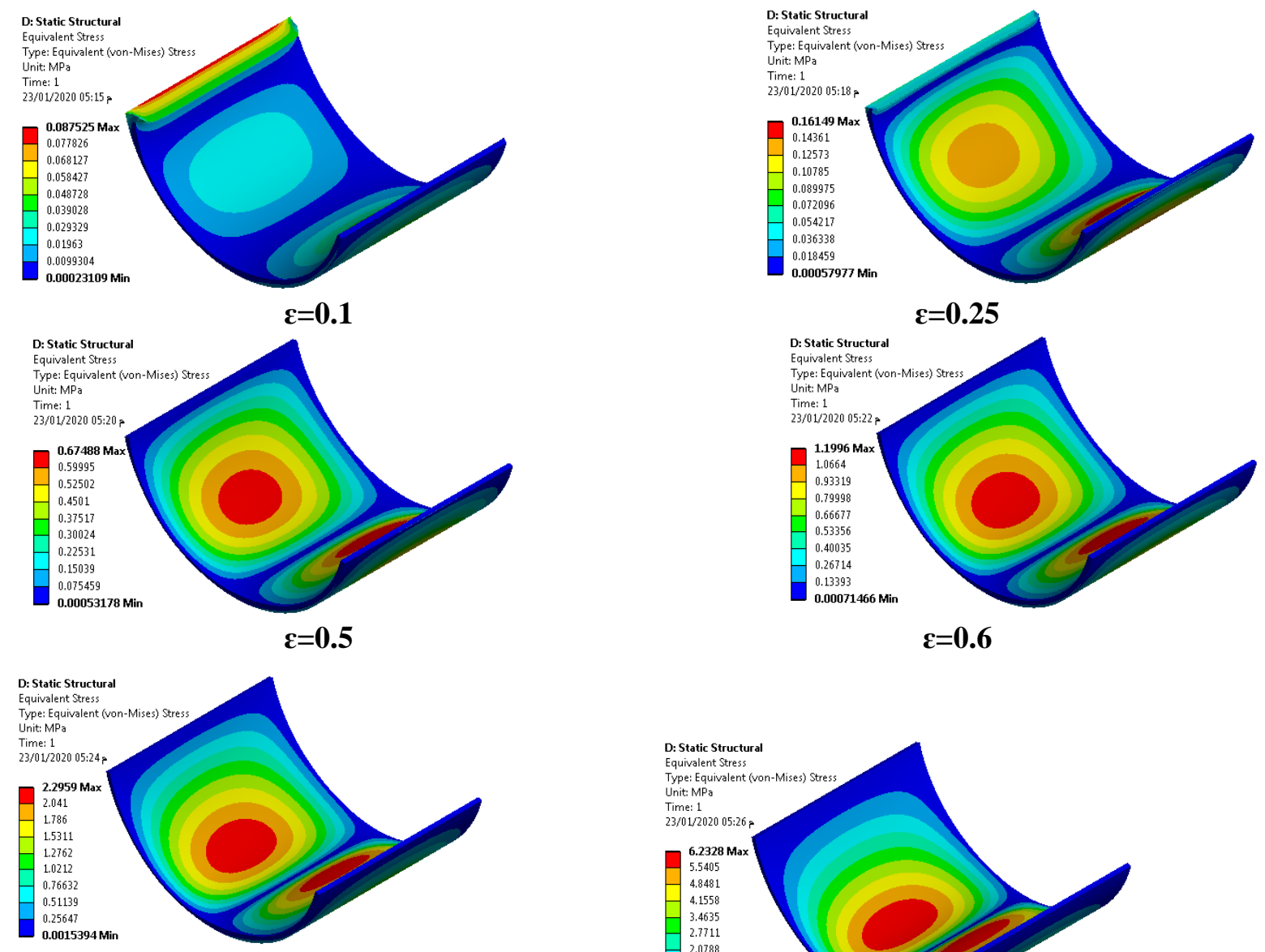

$\varepsilon=0.7$

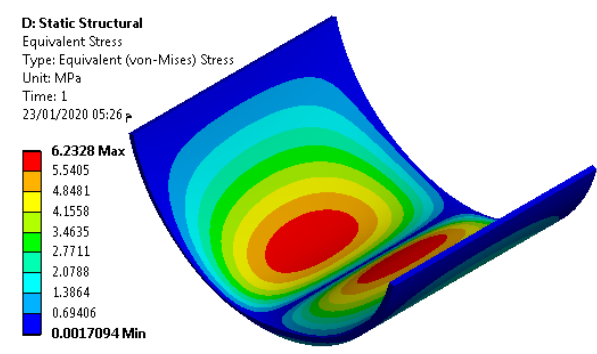

$\varepsilon=0.82$

Fig. 15. Equivalent stress at various eccentricity ratios for $150^{\circ}$ arc bearing. 

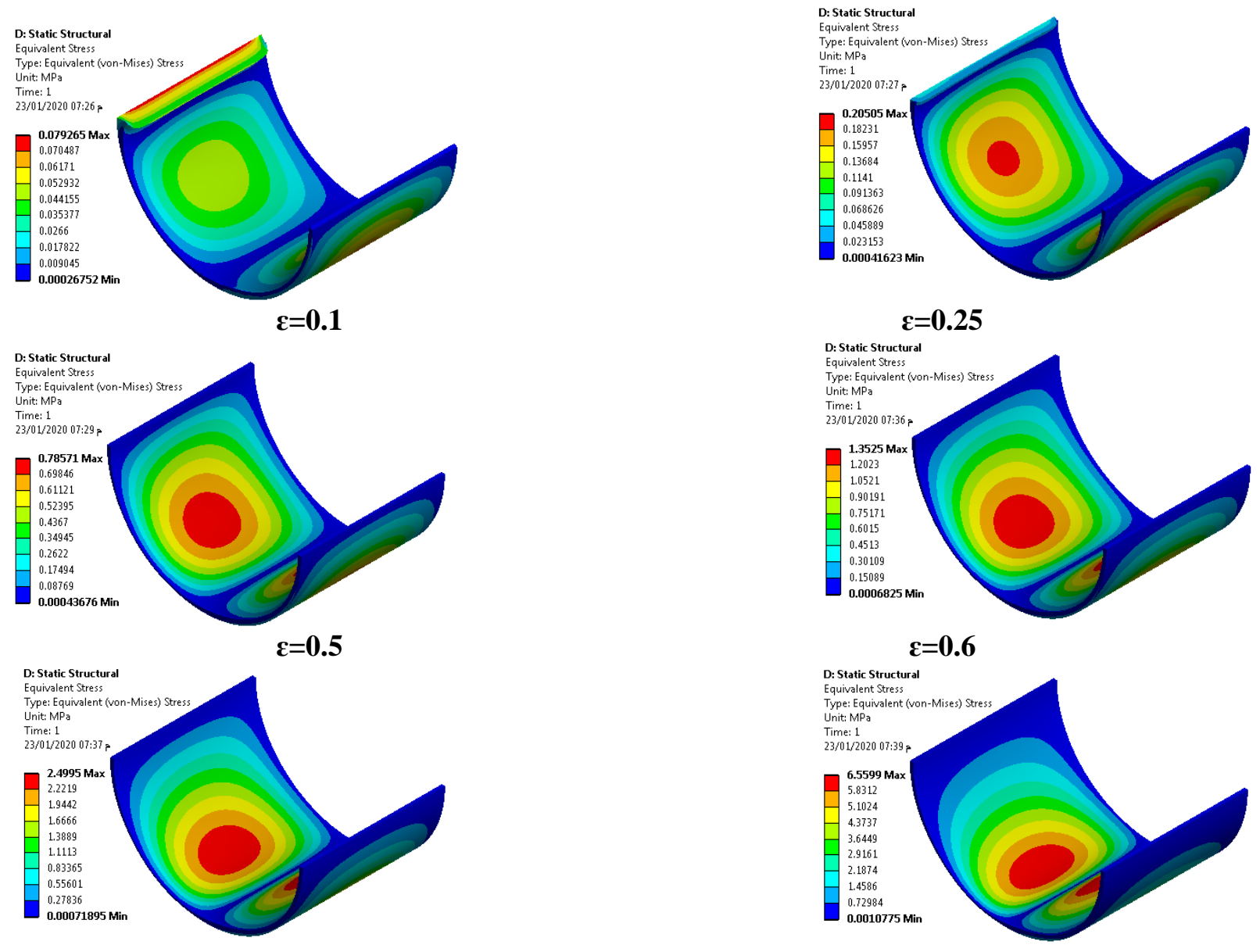

$\varepsilon=0.7$

$\varepsilon=0.82$

Fig. 16. Equivalent stress at various eccentricity ratios for $180^{\circ}$ arc bearing.
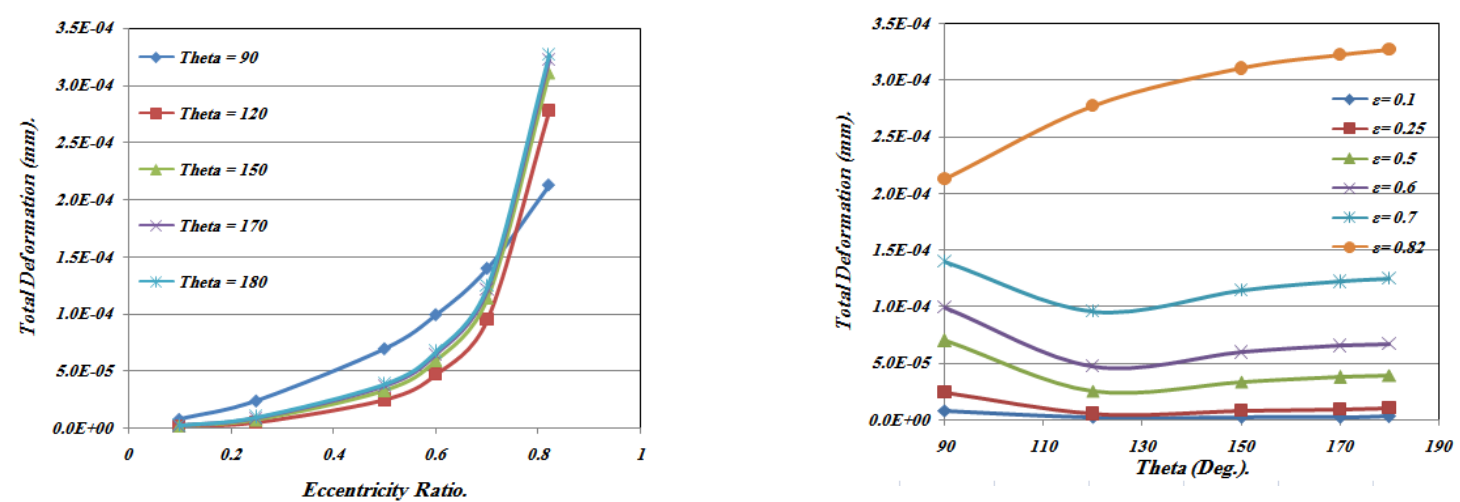

Fig. 17. Effect of eccentricity ratio (left) and arc bearing angle (right) on the total deformation distribution on the inner surface of bearing.

As the bearing is stressed due to the load exerted over its inner surface, a deformation is generated as a result of the non-uniform distribution of the lubricant pressure over that surface. The three-dimensional distribution of the deformation generated is illustrated in set Figs. 18-20 for various values of eccentricity ratio and arc bearing angle. As the deformation is an expected 
outcome of the stress applied, its values are raised with the increase in the eccentricity ratio, as demonstrated earlier in Fig. 17. The deformation is increased as well with the increase in both the eccentricity ratio and arc bearing angle.

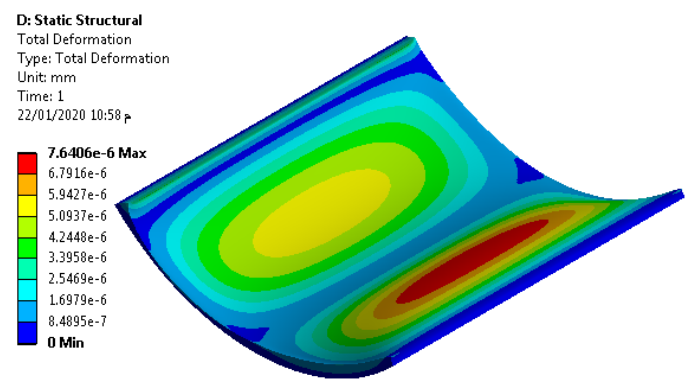

$$
\varepsilon=0.1
$$
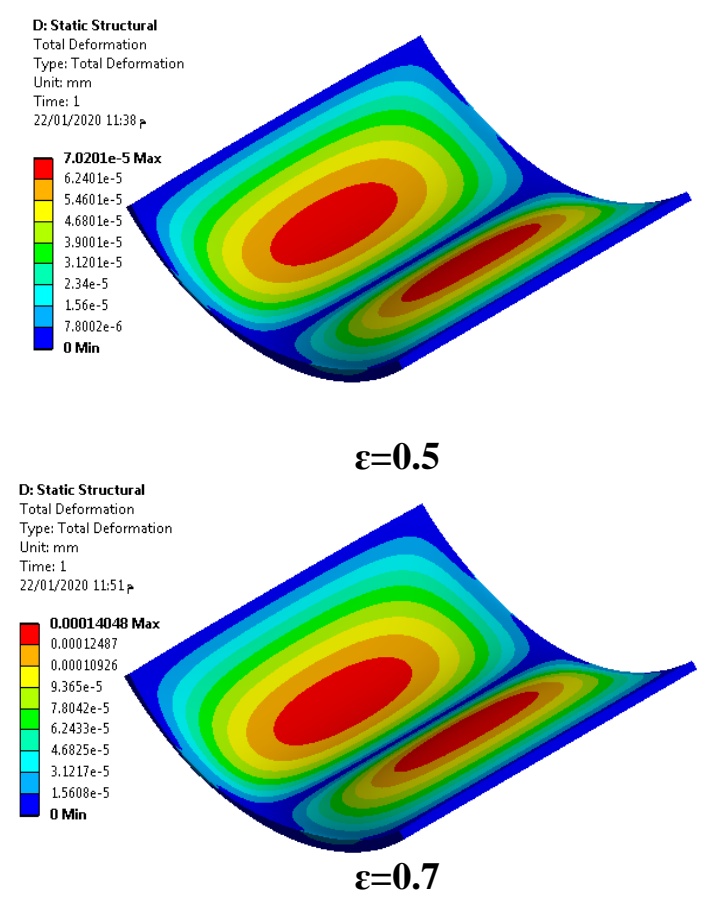

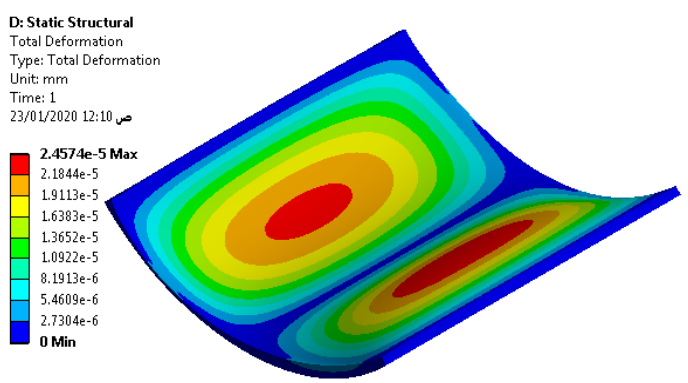

$\varepsilon=0.25$
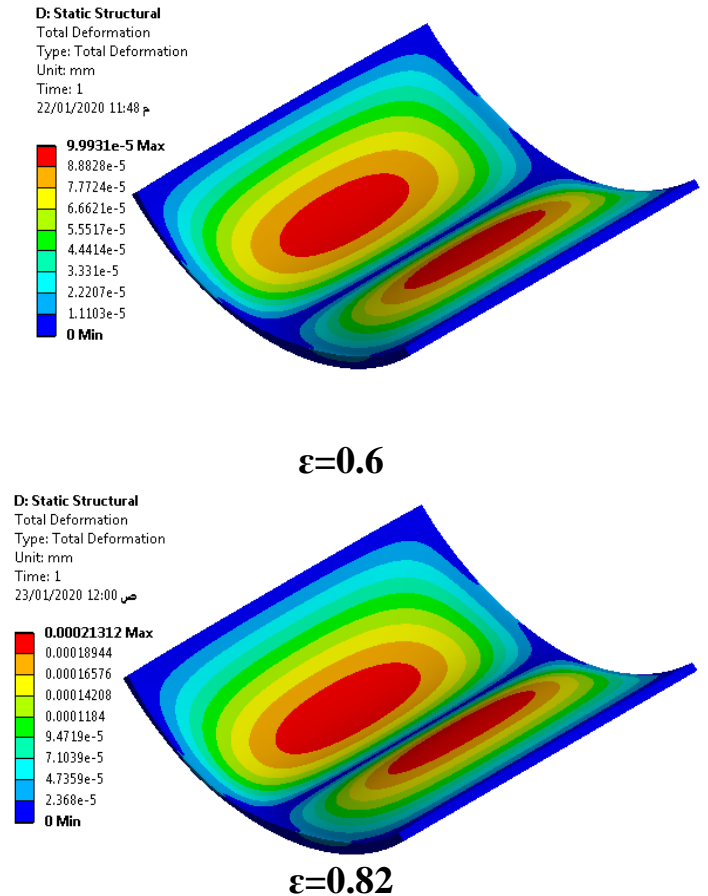

Fig. 18. Total deformation at various eccentricity ratios for $90^{\circ}$ arc bearing. 
D: Static Structural Total Deformation Type: Total
Unit: $m$ m
Time: 1
23/01/2020

23/01/2020 12:39 ص
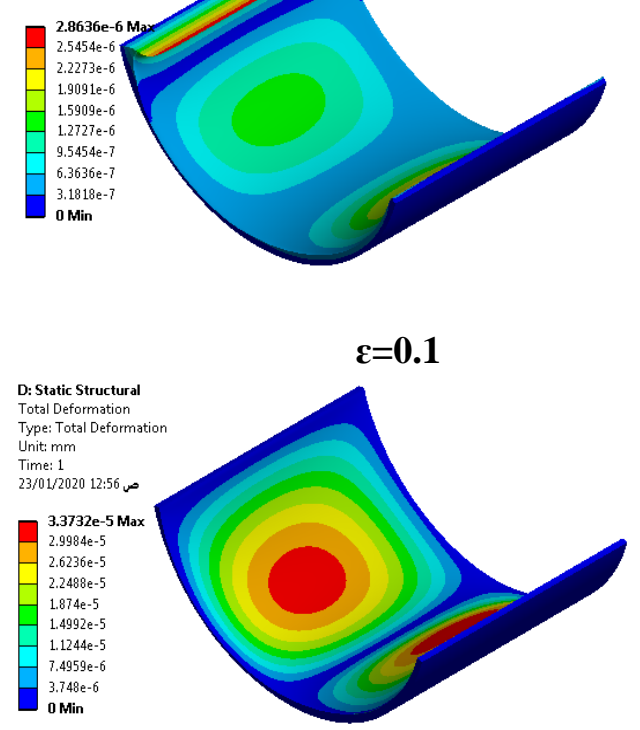

$\varepsilon=0.5$

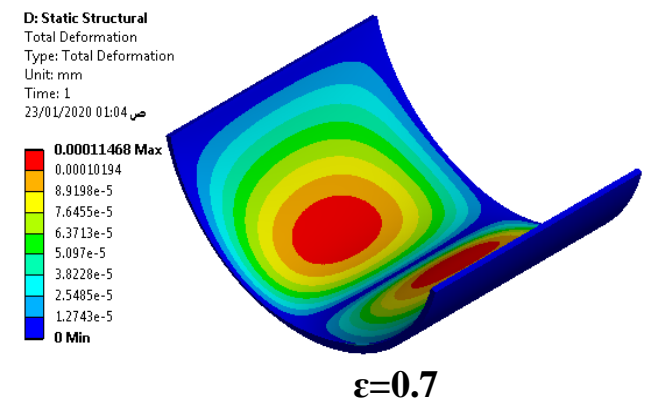

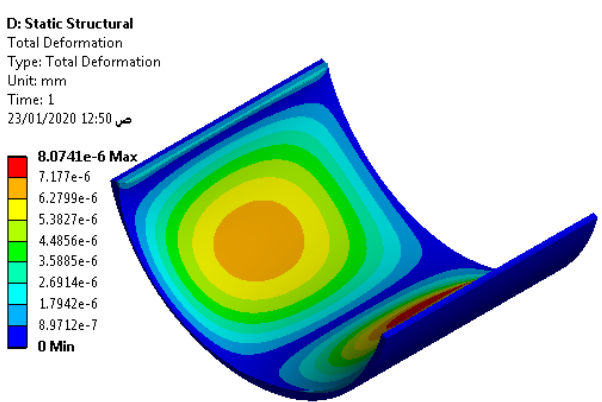

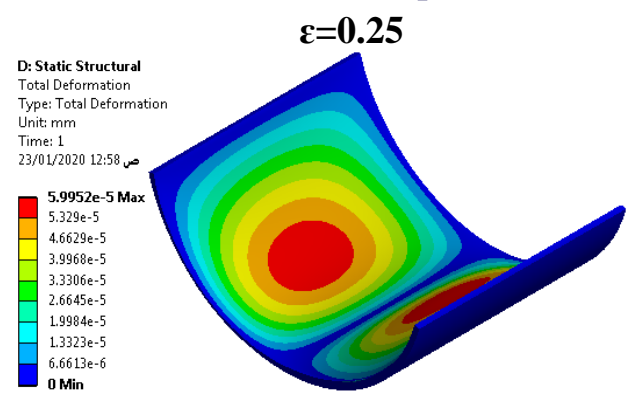

$$
\varepsilon=0.6
$$

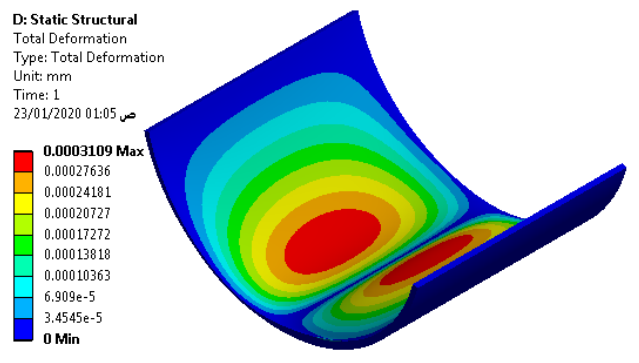

$\varepsilon=0.82$

Fig. 19. Total deformation at various eccentricity ratios for $150^{\circ}$ arc bearing. 

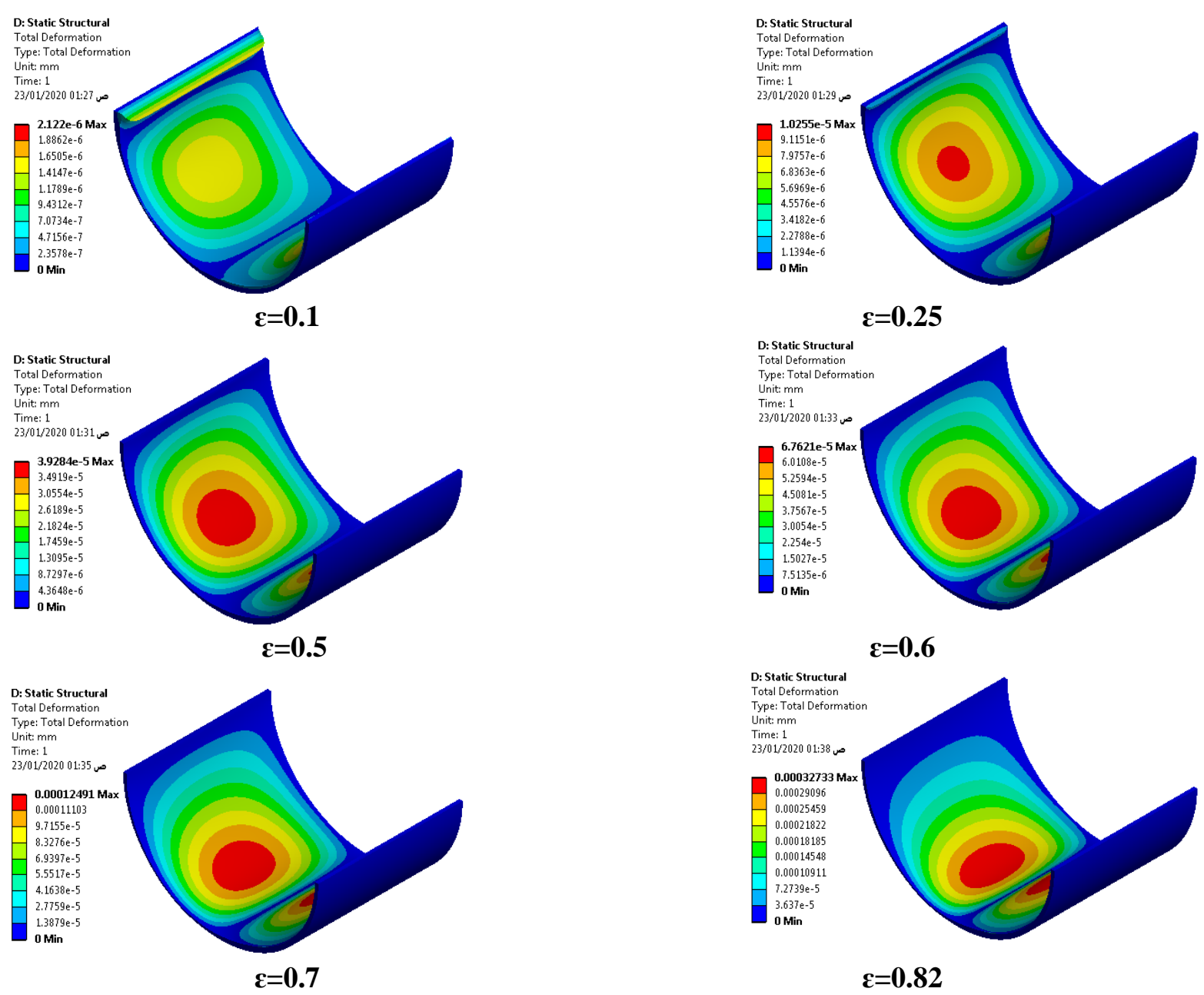

Fig. 20. Total deformation at various eccentricity ratios for $1^{\circ}$ arc bearing.

\section{CONCLUSIONS}

In the current FSI analysis, the lubricant flow has been predicted according to the finite_volume method, which is considered steady state, incompressible and laminar. while the finite element method has been adopted to compute the deformation and stress in the bearing surface. On the basis on the results that are arrived at in the present study, the following conclusions are given: 1. The fluid -solid interaction technique used in present work is good enough to predict the performance of finite partial journal bearings which give more accurate results.

2. It is observed that the hydrodynamic pressure is affected by arc bearing angle $(\theta)$ and eccentricity ratio $(\varepsilon)$ where the hydrodynamic pressure is increased linearity with the increase in arc bearing angle $(\theta)$ and eccentricity ratio $(\varepsilon)$.

3. The deformation and stress in inner bearing surface resulted due to the hydrodynamic pressure generated and increase linearity with the pressure increase. 


\section{REFERENCES}

Yu, T.S. and Szeri, A.Z. (1975) 'Partial Journal Bearing Performance in the Laminar Regime', Trans. ASME, (74), 94-100.

Suganami, T. and Szeri. A. Z. ( 1979)'A Parametric Study of Journal Bearing Performance: The 80 Deg Partial Arc Bearing', Trans. ASME, 101, 486-491.

Malik, M.,Chandra,M.and Sinhasan,R. (1981) 'ANALYSIS OFA CENTRALLY LOADED I20 DEGREE PARTIAL POROUS JOURNAL BEARING TAKING TANGENTIAL VELOCITY SLIP INTO ACCOUNT', Mech. Eng. Sci., 23(4), 171-178.

Jain, S. C.,Sinhasan,R.and Singh,D.V. (1982) 'Elasto-hydrodynamic lubrication analysis of partial arc journal bearings', Tribol. Int., 161-168.

Jain, S. C., Sinhasan,R.and Singh,D.V,PHD. (1983) 'A study of elastohydrodynamic lubrication of a centrally loaded 120 arc partial bearing in different flow regimes', Eng. Sci. Div., 197(2), 97-108.

Khonsari,M.M.,Jang,J.Y.andFillon,M.(1996)'On the Generalization of Thermohydrodynamic Analyses for Journal Bearings', J. Tribol., 118, 571-579.

Dobrica, M. B., Fillon,M.and Maspeyrot,P.(2006) 'MIXED EHD LUBRICATION IN A PARTIAL JOURNAL BEARING - COMPARISON BETWEEN DETERMINISTIC AND STOCHASTIC MODELS', Trans. ASME, 1-12.

Patir, N. and Cheng, H. S.(1978) 'An Average for Awerage Flow Model iodel for Determining Effects of Three- Dimensional Roughness on on Partial Hydrodynamic Lubrication I',Trans. ASME, 100, 12-17.

Bhat,P.,ShenoyB,S.andPai,R.(2007)'ELASTOHYDRODYNAMICLUBRICATIONANALYSIS OF A RADIALY ADJUSTABLE PARTIAL ARC BEARING USING FLUID STRUCTURE INTERACTION', Proc. ASME/STLE Int. Jt. Tribol. Conf., 1-3.

Dobrica, M.B. and Fillon, M.(2008) 'INFLUENCE OF SCRATCHES ON THE PERFORMANCE OF A PARTIAL JOURNAL BEARING', ASME, 1-3.

Abass,B.A.,Hosain,A.M.andSadiq,B.R.(2010) 'SURFACE TEMPERATURE EFFECT ON THE THERMOHYDRODYNAMIC PERFORMANCE OF JOURNAL BEARING IN HEAVY DUTY MACHINERY', J. Eng., 16(4),6071-6084.

Dobrica, M. B. and Fillon, M. (2012) 'Performance degradation in scratched journal bearings', Tribology International. Elsevier, 51, 1-10. doi: 10.1016/j.triboint.2012.02.003.

Liang, X.,Liu,Z.,Wang, H.,Zhou,X. and Zhou, X.( 2016) "Hydrodynamic lubrication of partial textured sliding journal bearing based on three-dimensional CFD," Ind. Lubr. Tribol., 68(1), $106-115$. 
Versteeg, H. K. and Malalasekera, M. (2007) An Introduction to Computational Fluid Dynamics: The Finite Volumes Method. 2nd ed., Essex: Pearson Education Limited.

Liu, H., Xu, H., Ellison, P. J. and Jin, Z. (2010) 'Application of Computational Fluid Dynamics and Fluid - Structure Interaction Method to the Lubrication Study of a Rotor - Bearing System', Tribology Letters,38 (3), 325-336. doi: 10.1007/s11249-010-9612-6. 